\title{
Preoperative glucose abnormalities in patients with pancreatic tumours
}

\author{
Marta A. Matejak-Górska ${ }^{1}$, Marek Durlik ${ }^{1,2}$, Bernadetta Kałuża³, Alicja Milczarczyk², Edward Franek ${ }^{3,4}$ \\ ${ }^{1}$ Clinical Department of Gastroenterology Surgery and Transplantation, Central Clinical Hospital of Interior, Warsaw, Poland \\ 2Department of Surgical Research and Transplantology, Mossakowski Medical Research Centre Polish Academy of Sciences, \\ Warsaw, Poland \\ ${ }^{3}$ Clinical Department of Internal Diseases, Endocrinology and Diabetology, Central Clinical Hospital of Interior, Warsaw, Poland \\ ${ }^{4}$ Department of Human Epigenetics, Mossakowski Medical Research Centre Polish Academy of Sciences, Warsaw, Poland
}

Prz Gastroenterol 2014; 9 (2): 105-108

DOI 10.5114/pg.2014.42506

Key words: pancreatic cancer, diabetes, surgery, pancreatitis, pancreatic cancer screening, risk factors for pancreatic cancer.

Address for correspondence: Marta A. Matejak-Górska, Clinical Department of Gastroenterology Surgery and Transplantation, Central Clinical Hospital of Interior, 137 Wołoska St, 02-507 Warsaw, Poland, phone: +48 502569 666, e-mail: mmatejak74@tlen.pl

\begin{abstract}
Introduction: Pancreatic cancer is a neoplasm characterised by poor prognosis. The only effective, possible treatment is radical surgery, but most patients do not qualify for surgery because of delayed diagnosis.

Aim: To determine if assessment of endocrine pancreatic function could serve as a means of screening for pancreatic cancer.

Material and methods: This prospective study was conducted on a group of 50 patients diagnosed with pancreatic tumour, who were qualified for surgery.

Results: From 1.07.2010 to 4.07.2011 a further 50 patients were added to the study group. They had been admitted to the hospital with pancreatic tumours. During the preoperative period, nine of these people had been treated for diabetes, 14 were newly diagnosed with diabetes and 15 had been diagnosed with impaired glucose tolerance, but only 12 had a normal glucose profile. Afterwards, patients underwent the surgical treatment. Histopathological examination revealed that out of the 50 operated patients, 36 suffered from malignant disease, and of these only four had no impaired glucose tolerance before treatment.

Conclusions: In most cases, patients with pancreatic tumours have impaired glucose tolerance. Screening patients over 50 years of age could speed up diagnosis and surgical treatment.
\end{abstract}

\section{Introduction}

Pancreatic cancer is a cancer with poor prognosis, and a continuous increase in its morbidity has been observed in recent years. Despite the development of new imaging techniques and laboratory findings, diagnosis is often too late, making radical surgical treatment impossible to perform [1, 2]. Pancreatic tumours may originate from the exocrine and endocrine component of the pancreas. Most tumours of endocrine origin are located in the head (65\%) or in the body and tail of the pancreas (10\%). Endocrine tumours represent approximately $5 \%$ of cases, and have a much better prognosis. A separate group of pancreatic tumours includes duodenal bulb, greater duodenal papilla tumours (Vater), the distal part of the common bile duct and the duodenum; they account for about $25 \%$ of all pancreatic tumours [1]. The prognosis for pancreatic cancer is poor, with about
$10 \%$ of patients surviving one year after diagnosis, and 5 -year survival is less than $5 \%$ [3]. The only effective treatment for pancreatic cancer is surgery, but often, due to the clinical stage and infiltration of vital structures, surgical resection is not possible. The greatest possibility of radical surgery is for patients with pancreatic cancer of Vater's papilla, in which diagnosis is early and the resectability of the tumour increases up to $90 \%$ [3]. According to the Centre of Oncology in Warsaw in 2009, pancreatic cancer accounted for $2.4 \%$ of all cancers. Pancreatic cancer is the eighth most common cancer in men, and the ninth most common in women, and it is the sixth leading cause of cancer-related deaths in men and the fifth in women [4]. In industrialised countries, the incidence rate is $8-12 / 100,000$; in Poland there are around 3,500 new cases per year [4]. Incidence increases with age, and the largest number of people affected are 
in the seventh and eighth decades of life. It is therefore important to determine the possible factors which can contribute to the diagnosis and initiation of treatment.

Such factors may include diabetes. The occurrence of pancreatic cancer is associated with diabetes and impaired glucose metabolism. On the one hand, the destruction of pancreatic islets by cancer, pancreatic duct obstruction, and humoral effects of tumour tissue in apparently healthy pancreatic parenchyma may cause impaired glucose (this probably occurs in the majority of pancreatic cancer patients). On the other hand, existing diabetes can accelerate the progression of pancreatic cancer by a variety of mechanisms, e.g. advanced glycation end products (the concentration of which is significantly increased in diabetes) may increase the ability of tumour cells to metastasise [5].

\section{Aim}

The aim of this study was to determine if assessment of endocrine pancreatic function could serve as a means of screening for pancreatic cancer.

\section{Material and methods}

The Department of Gastroenterological Surgery and Transplantation Central Clinical Hospital of Interior in Warsaw annually performs about 200 operations on patients with various diseases of the pancreas. The study included 50 consecutive patients with pancreatic tumours who were scheduled for surgery in the Department of Gastroenterological Surgery and Transplantation Central Clinical Hospital of Interior in Warsaw between 1.07.2010 and 4.07.2011 and who had given their informed consent to participate in a clinical trial. Studies were conducted on each patient before surgery to evaluate carbohydrate metabolism and its alignment, as well as pancreatic endocrine function. All patients who were not previously diagnosed with diabetes mellitus underwent oral random or fasting glucose tests. Depending on the results of these tests, patients were diagnosed with type 2 diabetes, impaired glucose metabolism or proper carbohydrate metabolism. Diabetes was diagnosed in accordance with the standards of the Polish Diabetes Association. In order to determine the alignment of glucose, their glycated haemoglobin levels $\left(\mathrm{HbA}_{1 \mathrm{c}} \%\right)$ were measured. In order to determine the activity of the endocrine pancreas, C-peptide concentrations were measured after fasting and $2 \mathrm{~h}$ after breakfast. Patients were characterised by age, sex, body mass index (BMI) and serum tumour markers (CEA carcinogenic antigen, Ca 19-9). The type of surgery treatment as well as the results of a histopathological examination were included in the analysis, and depending on the results, patients were divided into two groups. Group 1 - Patients with pancreatic ductal carcinoma (adenocarcinoma) - 27 subjects (54\%), and group 2 - patients with other histopathological diagnosis 23 subjects (46\%) including the following: ampullary carcinoma $(n=3)$, cancer of the bile duct and the duodenum $(n=3)$, other tumours $(n=3)$, chronic pancreatitis $(n=7)$, intraductal papillary mucinous neoplasm (IPMN; $n=2$ ), gastrointestinal stromal tumors (GIST; $n=1)$, benign pancreatic cysts $(n=3)$ and other $(n=1)$.

General characteristics: 13 women, 37 men, mean age 61.2 years (31-81 years), 61.9 years for women and 60.9 years for men. In the analysis the results of preoperative tests and their dependence on histopathological findings were presented. In accordance with the principles of surgery for pancreatic tumours $[1-3,6]$, depending on the location of the lesion and the clinical stage, the following treatments were performed on patients: pancreatoduodenectomy (31), distal resection of the pancreas (6), total pancreatectomy (6), drainage operations (1), and bypass anastomosis and pancreatic biopsies (6).

The study received approval from the Bioethics Committee operating at Central Clinical Hospital of Interior in Warsaw.

\section{Statistical analysis}

Statistical analysis was performed according to the type of data; the Mann-Whitney test or $\chi^{2}$ test was used. A significant difference was defined as $p<0.05$. Statistical software Statistica 6 was used.

\section{Results}

After surgery the patients were in hospital for an average of 7.1 days (3-30). The analysis of the data collected during the preoperative period shows that in this group 9 patients had been treated for diabetes, 15 diagnosed with various forms of impaired glucose tolerance and 14 newly diagnosed with diabetes on the basis of laboratory diagnosis. Among the operated patients with tumours of the pancreas, only 12 had not suffered from disorders of carbohydrate metabolism before the surgery. Patients with pancreatic cancer differed significantly in statistical terms from the other patients with newly diagnosed diabetes, with regard to the absence of glucose metabolism as well as the concentration of tumour markers CEA and CA 19-9. Patients with adenocarcinoma showed a much higher percentage of newly diagnosed diabetes (Table I).

\section{Discussion}

The most common cancer of the pancreas is adenocarcinoma, which accounts for up to $85 \%$ of all proliferative diseases of the pancreas and affects about $3 \%$ of 
Table I. Statistical analysis of the patientgroups: adenocarcinoma and other tumours

\begin{tabular}{|c|c|c|c|}
\hline Features & $\begin{array}{c}\text { Adenocarcinoma } \\
N=27(54 \%)\end{array}$ & $\begin{array}{l}\text { Other tumors } \\
N=23(46 \%)\end{array}$ & Value of $p$ \\
\hline Sex: male, $n(\%)$ & $21(77.7)$ & $16(69.6)$ & 0.62 \\
\hline Age, mean \pm SD [years] & $63.26 \pm 9.5$ & $58.69 \pm 11.46$ & 0.11 \\
\hline $\mathrm{BMI}$, mean $\pm \mathrm{SD}\left[\mathrm{kg} / \mathrm{m}^{2}\right]$ & $23.98 \pm 4.27$ & $24.9 \pm 5.3$ & 0.5 \\
\hline Whipple's procedure, $n(\%)$ & $17(62.9)$ & $14(60.9)$ & \\
\hline Distal surgery, $n(\%)$ & $1(3.7)$ & $5(21.7)$ & \\
\hline Bypass operation, $n(\%)$ & $3(11.1)$ & $0(0)$ & \\
\hline Frey's procedure, $n(\%)$ & $0(0)$ & $1(4.3)$ & \\
\hline Laparotomy with biopsy, $n$ (\%) & $2(7.4)$ & $1(4.3)$ & \\
\hline Total pancreatectomy, $n(\%)$ & $4(14.8)$ & $2(8.7)$ & \\
\hline Pre-DM, $n(\%)$ & $3(11.1)$ & $6(26.1)$ & 0.17 \\
\hline $\mathrm{DM}, n(\%)$ & $13(48.1)$ & $1(4.3)$ & 0.00058 \\
\hline Disturbances in carbohydrate metabolism, $n(\%)$ & $9(33.3)$ & $6(26.1)$ & 0.57 \\
\hline Without disturbances in carbohydrate metabolism, $n$ (\%) & $2(7.4)$ & $10(43.5)$ & 0.0029 \\
\hline CEA, median $\left(25^{\text {th }}-75^{\text {th }} I Q R\right)$ & $3.9(2.87-8.52)$ & $2.62(1.07-4.53)$ & 0.044 \\
\hline Ca $19-9$, median ( $\left.25^{\text {th }}-75^{\text {th }} I Q R\right)$ & $142.3(10.2-1098)$ & $11.5(5.4-22.9)$ & 0.0021 \\
\hline Fasting C peptide, median ( $25^{\text {th }}-75^{\text {th }}$ IQR) & $1.72(0.89-2.9)$ & $1.91(1.39-2.92)$ & 0.51 \\
\hline $\mathrm{C}$ - peptide $2 \mathrm{~h}$ after breakfast, median $\left(25^{\text {th }}-75^{\text {th }} \mathrm{IQR}\right)$ & $4.42(2.56-6.95)$ & $5.12(3.22-7.05)$ & 0.47 \\
\hline $\mathrm{HbA}_{1 \mathrm{c}} \%$, median $\left(25^{\text {th }}-75^{\text {th }} \mathrm{IQR}\right)$ & $6.25(5.4-7.55)$ & $5.7(5.45-6.55)$ & 0.37 \\
\hline
\end{tabular}

Pre-DM - previous diabetes mellitus, $D M$ - newly diagnosed diabetes mellitus

all malignant tumours [7]. It is derived from epithelial tissue lining the exocrine pancreas and is characterised by a low rate of long-term survival [8]. Poor prognosis is directly associated with a few proven risk factors, symptoms (though they are of low specificity) as well as unresectability during diagnosis [7-9]. Of all patients diagnosed with adenocarcinoma, only about $20 \%$ could undergo radical treatment, while palliative surgery to allow flow of bile or gastrointestinal patency was performed on the rest [7-11].

Among the documented risk factors for adenocarcinoma are age (60-80 years old), smoking and congenital pancreatitis. Other factors include diabetes and chronic pancreatitis, a high-fat diet, exposure to carcinogens and, according to some sources, coffee and alcohol abuse [7-11]. Typical, specific symptoms include pain, obstructive jaundice and weight loss (the first two of these symptoms may be dependent on the location of the tumour in the pancreas).

In view of such data, as well as the increasing rate of morbidity [10-12], it seems necessary to search for new risk factors, as well as to document the relationship between pancreatic cancer and other, already discovered factors. This paper is concerned with diabetes.

In the group we studied 45 patients (90\% of the group) were 50 years of age or more. In 4 people under
50 years of age there were no disturbances of carbohydrate, and only 1 person was newly diagnosed with diabetes. In the following age groups disturbances of glucose metabolism related to the majority of patients. It was found that of the 50 patients undergoing surgery 36 (72\%) were diagnosed with cancer. In this group, preoperative glucose metabolism disorders related to 32 patients (89\%), of which only 6 people had previously been treated for diabetes: 2 patients - oral hypoglycemics, 4 patients - insulin therapy, 13 patients - newly diagnosed diabetes, and 13 patients - disorders of carbohydrate metabolism. A large percentage of patients (89\%) with abnormal glucose metabolism may indicate a close relationship of these disorders with pancreatic adenocarcinoma.

Reports suggest that a higher incidencenot only of pancreatic cancer has been observed in diabetic patients, but also of primary liver cancer, colorectal cancer, breast cancer and cancer of the endometrium $[11,13,14]$. It seems that the underlying carcinogenesis in these patients is secondary to hyperinsulinism [12-14]. It has been proven that an increase in BMI for each $5 \mathrm{~kg} / \mathrm{m}^{2}$ significantly raises the risk of malignancy, including that of the pancreas [10]. Insulin has mitogenic activity, stimulates the cells to divide by kinase - MAP, as well as being a growth factor inhibiting apoptosis by influencing protein IGF [12, 14-18]. Oncogenic function may also have hyperglycaemia at the 
molecular level through the induction of DNA synthesis of tumour or free radicals, and by the devastating effects on DNA repair enzymes [12, 14, 16-18]. The same effects as a chronic disease such as diabetes with gastroparesis is also significant [14]. It appears that diabetes most greatly increases the risk of pancreatic cancer in the first decade of its duration $[9,10]$.

Sometimes we deal with a so-called reverse causal relationship, where the cause of diabetes is a tumour of the pancreas $[10,11]$. It is estimated that approximately $23 \%$ of patients with pancreatic adenocarcinoma have diabetes, the history of which improves significantly after resection of the tumour. It is also worth mentioning that diabetes occurs as a symptom, regardless of the location of the tumour in the pancreas [9-11]. The genesis of this phenomenon is based on the destructive action of tumour cells on normal pancreatic parenchyma, as well as through the production of an amyloid peptide island, which reduces insulin sensitivity [10,12,16] and other factors [5].

A specific gene responsible for the development of pancreatic tumours has not yet been determined. However, it has been observed that a genetic predisposition may play a role in this process. There is still an increased risk of pancreatic cancer in patients with hereditary pancreatitis, familial atypical multiple-mole melanoma syndrome (FAMMM syndrome), the von Hippel-Lindau group and a family history of breast cancer [10]. To ascertain the common features of diabetes and pancreatic tumours, the genetic relationship between these diseases was also studied. It is likely that the glucokinase regulatory gene (GCKR) corresponds to the nucleotide polymorphism [19], and it was further demonstrated that the genotype GG PPAR $\gamma$ P12A is inversely correlated with the risk of pancreatic cancer, as well as some variants of NR5A2 [20]. However, the impact of gene FTO and ADIPOQ pancreatic cancer development is dependent on the presence of obesity.

\section{Conclusions}

Regardless of whether diabetes is a risk factor or a symptom of pancreatic tumours, it seems that there is an inseparable relationship, and in order to increase the percentage of successful radical resection of the tumour, all patients with newly diagnosed impaired glucose metabolism, a history of cigarette smoking and weight loss should undergo detailed imaging of the pancreas for final diagnosis.

\section{References}

1. http://epid.coi.waw.pl/km

2. Sener SF. Pancreatic cancer: a report of treatment and survival trends for 100,313 patients diagnosed from 1985-1995, using the national cancer database. Am Coll Surg 1999; 189: 1-7.
3. Bramhall SR, Allum WH, Jones AG, et al. Treatment and survival in 13560 patients with pancreatic cancer, and incidence of the disease in the west Midlands: an epidemiological study. Br J Surg 1995; 82: 111-5.

4. Diakowska J, Wojciechowska U, Zatoński W. Nowotwory złośliwe w Polsce w 2009 roku, Krajowy Rejestr Nowotworów. Publikacja wydana w ramach zadania "Rejestracja nowotworów złośliwych” Narodowego Programu Zwalczania Chorób nowotworowych, Warsaw 2011.

5. Li J, Cao G, Ma Q, et al. The bidirectional interaction between pancreatic cancer and diabetes. Word J Surg Oncol 2012; 10: 171.

6. Andren-Sandberg A, Hedbrg M, Jurałowicz P, et al. Surgical treatment of pancreatic cancer - randomized controlled trials [Polish]. Prz Gastroenterol 2011; 6: 133-8.

7. Kordek J (ed.): Pancreatic cancer. In: Oncology. Manual for students and physicians [Polish]. Via Medica, Gdańsk 2007; 197-202.

8. Robbins patology (Polish edition). Urban and Partner, Wrocław 2005; 731-55.

9. Nehring P, Makowski A, Mrozikiewicz-Rakowska B, et al. A new look at the etiopathogenesis and diagnosis of adenocarcinoma of the pancreas [Polish]. Nowa Klinika, Diabetologia, Gastroenterologia, Otyłość 2000; 18: 62-6.

10. Rydzewska G. Risk factor for pancreatic cancer. Gastroenterol Pol 2007; 14: 368-71.

11. Giovannucci E, Harlan DM, Archer MC, et al. Diabetes and cancer. A consensus report. Diabetes Care 2010; 33: 1674-85.

12. Donghui L. Diabetes and pancreatic cancer. Mol Carcinog 2012; 51: 64-74.

13. Dąbrowski M. Diabetes and cancer [Polish]. Diabet Prakt 2010; 11: 54-63.

14. Metabolic syndrome [Polish]. Mamcarz A (ed.). Medical Education, Warsaw 2008; 579-86.

15. Renehan AG, Tyson M, Egger $M$, et al. Body mass index and incidence of cancer: a systematic review and meta - analysis of prospective observational studies. Lancet 2008; 371: 569-78.

16. Cui Y, Andersen DK. Diabetes and pancreatic cancer. Endocr Relat Cancer 2012; 19: F9-26.

17. Liang H, Qingyong M, Junhui L, et al. High glucose promotes pancreatic cancer cell proliferation via the induction of EGF expression and transactivation of EGFR. PLOS One 2011; 11: e27074.

18. Manami I, Shoichiro T. Insulin resistance and cancer: epidemiological evidence. Endocr Relat Cancer 2012; 19: 1-8.

19. Prizment AE, Gross M, Rasmussen-Torvik L, et al. Genes related to diabetes may be associated with pancreatic cancer in a population - based case - control study in Minnesota. Pancreas 2012; 41: 50-3.

20. Hongwei T, Xiaoqun D, Hassan M, et al. Body mass index and obesity - and diabetes - associated genotypes and risk for pancreatic cancer. Cancer Epidemiol Biomarkers Prev 2011; 20: 779-92.

Received: 14.06 .2013

Accepted: 26.09 .2013 